\title{
Histological Pattern and Outcome of Filipino Children with Liver Disease Who Underwent Percutaneous Liver Biopsy: A Five Year Survey
}

\author{
Judy Lyn D. Vitug, ${ }^{1}$ Jose Ma. C. Avila² and Germana V. Gregorio ${ }^{1}$ \\ ${ }^{1}$ Section of Pediatric Gastroenterology, Hepatology and Nutrition, Department of Pediatrics, \\ College of Medicine and Philippine General Hospital, University of the Philippines Manila \\ ${ }^{2}$ Department of Pathology, College of Medicine, University of the Philippines Manila
}

\begin{abstract}
Background. Histological assessment is important in evaluating liver disease. We determined the clinical diagnoses and predominant histological patterns of children with liver disease and association of histological pattern with outcome.
\end{abstract}

Methods. Consecutive patients $<19$ years who had liver biopsy were included. Clinical diagnoses were determined. Histological assessment was done using nine patterns to describe histopathologic changes. Outcome was assessed at least 6 months after diagnosis.

Results. 470 cases (1month-18years; 65\% males; 85\% <1year) were included. Most common clinical diagnoses were neonatal hepatitis (49\%) and biliary atresia (29\%). 229 neonatal hepatitis with giant cell pattern had better outcome $(96 \%$ alive after 1 year vs. 136 biliary atresia with obstructive/ fibrotic pattern of whom $74 \%$ died, $\mathrm{p}=<0.05$ ). In the other disorders namely Alagille's syndrome, bile duct abnormalities, liver tumor and both chronic hepatitis and portal vein thrombosis, the predominant histologies were bile duct paucity, fibrotic, neoplastic and near normal patterns, respectively. In these cases, association with outcome could not be done due to limited patients.

Conclusion. Most common clinical diagnoses were neonatal hepatitis and biliary atresia. Predominant histological patterns were giant cell and obstructive type. Histological pattern of giant cell hepatitis seen in neonatal hepatitis resulted in better outcome.

Key Words: histopathologic pattern, liver biopsy, neonatal hepatitis, biliary atresia

Poster won at the 10th Biennial Convention of the Philippine Society of Pediatric Gastroenterology, Hepatology and Nutrition, March 2014.

Corresponding author: Germana V. Gregorio, MD

Section of Pediatric Gastroenterology, Hepatology and Nutrition

Department of Pediatrics

Philippine General Hospital

University of the Philippines Manila

Taft Avenue, Ermita, Manila 1000 Philippines

Telephone: +632 3531605

Fax No: +632 5260150

Email: germana1@hotmail.com
Introduction

The timely recognition of liver disease in pediatric patients still remains a major problem worldwide. In developed countries, like England and the United States of America, it has been reported that the absence of comprehensive data contributed to the late referral of infants with extrahepatic biliary atresia and other liver disorders leading to an unfavorable outcome..$^{1,2}$ Similarly, in developing countries infants with extrahepatic biliary atresia are mostly referred beyond the eight weeks golden period due to late diagnosis.3,4,5 An important component in the management of children with liver disease is the histological diagnosis in conjunction with the clinical and laboratory data. ${ }^{6}$

Liver biopsy is the histological assessment of the liver that has long been considered an integral component of the clinician's diagnostic armamentarium, even in the era of advanced virological, immunological and molecular genetic testing. It aids in establishing the diagnosis, in making therapeutic management decisions and in determining the patient's prognosis.,7-13 Currently, there are several methods to perform a liver biopsy. These vary depending on the route of how the specimen is obtained either as percutaneous through the intercostal or subcostal area, transvenous or transjugular or by laparoscopy. 7,14

The performance of the liver biopsy may have ultrasonographic guidance or it could be done blindly. Percutaneous liver biopsy without imaging assistance is excellent for diagnosing diffuse liver diseases such as hepatitis, cirrhosis, and metabolic diseases and the complication rate is low. ${ }^{6,15}$ However, it is not indicated for focal, discrete hepatic lesions, thus image guided biopsy is requested. ${ }^{16,17}$ The specimen is obtained using either aspiration or spring-loaded needles, such as the Menghini needle. ${ }^{18}$ The rate of complications after a percutaneous liver biopsy seems to be related to the experience of the physician and the type of needle used, the Menghini type needle being the safest. ${ }^{11-22}$ Scheimann reported that liver biopsy has an overall complication rate of $6.8 \%$ with a mortality rate of $0.4 \%{ }^{18}$ The major complications included hemothorax and intra abdominal hemorrhage while minor complications were pain in the incision site, fever within 24 hours after the 
procedure and rash, probably related to hypersensitivity to the anesthetic agent used. ${ }^{18}$

In the Philippines, there are no data on the burden of liver disease as to demographic characteristics, histological patterns, etiology and clinical outcome. The information obtained from this research will provide significant information on the prevalence of various pediatric liver diseases in a tertiary referral center in the country. Accurate knowledge of the type and nature of liver disease will help authorities formulate health care policies and prioritize health interventions, research and allocation of resources. ${ }^{2}$

At the Section of Pediatric Gastroenterology, Hepatology and Nutrition of the University of the Philippines Manila Philippine General Hospital, children suspected to have liver disease undergo biochemical and radiological investigations and if necessary, a liver biopsy to determine the histological pattern and the severity of the fibrosis and cirrhosis. This study determined the clinical diagnoses and predominant histological patterns among children with liver disease and the association of the histological pattern with outcome.

\section{Methods}

This investigation is both a retrospective (2006-8) and prospective (2009-10) cohort study conducted at the Section of Pediatric Gastroenterology, Hepatology and Nutrition in collaboration with the Department of Pathology of the University of the Philippines College of Medicine Philippine General Hospital. The study commenced after approval was obtained from the Expanded Hospital Research Office of the Philippine General Hospital. Only patients who gave their assent and/or whose guardians gave informed consent were included in the prospective part.

Consecutive patients $<19$ years old with liver disease who underwent percutaneous liver biopsy were included. For the retrospective part, the names of the patients who had a liver biopsy from January 2006 to December 2008 were obtained from the monthly census data of the section. The demographic, clinical, biochemical and histological features and outcome of the patients were determined either by review of medical records or upon enrolment in the study in the prospective part (January 2009 to December 2010). The patients were followed up until June 2011, which is at least six months from the last recruitment date. Patients with incomplete medical records, missing biopsy slides and with inadequate or poor processing of liver biopsy were excluded. An inadequate liver biopsy was defined as one that has less than five portal tracts in the specimen.

Liver biopsy and histological assessment. Before the liver biopsy procedure was done, complete blood count, blood typing, prothrombin time, liver function tests and ultrasound of the liver were done. Any bleeding abnormalities were corrected. The percutaneous liver biopsy was performed using standard procedure by an aspiration technique using the Menghini needle either blindly, ultrasound guided or with a mark at the biopsy site confirmed by ultrasound. All liver biopsies were performed by the Consultants or the Fellows of the Section. The patients were observed for six hours after the procedure for the presence of any complications related to the procedure.

The assessment of all the liver biopsies was done by a single pediatric histopathologist who only had the information on the patient's age. The needle biopsy specimen of the liver was evaluated under light microscope based on hematoxylin \& eosin staining. Additional staining was requested as necessary. The biopsy specimen was considered adequate if there were at least five portal tracts evaluated. The histological pattern proposed in this report was based on nine major histopathologic changes on pediatric liver biopsies done in our institution in the last 20 years (Table 1). A case maybe classified into one or more histological pattern as necessary, provided these are seen as predominant findings in the biopsy (Figure 1). Based on the clinical diagnoses of our patients and from available literature, it was postulated that these nine pre-established criteria were enough to make a reasonable histopathologic diagnosis of possibly $95 \%$ of all liver biopsy cases seen in the country. Each pattern as described can be seen in one or more liver diseases.

Table 1. Histopathologic Pattern and Definition

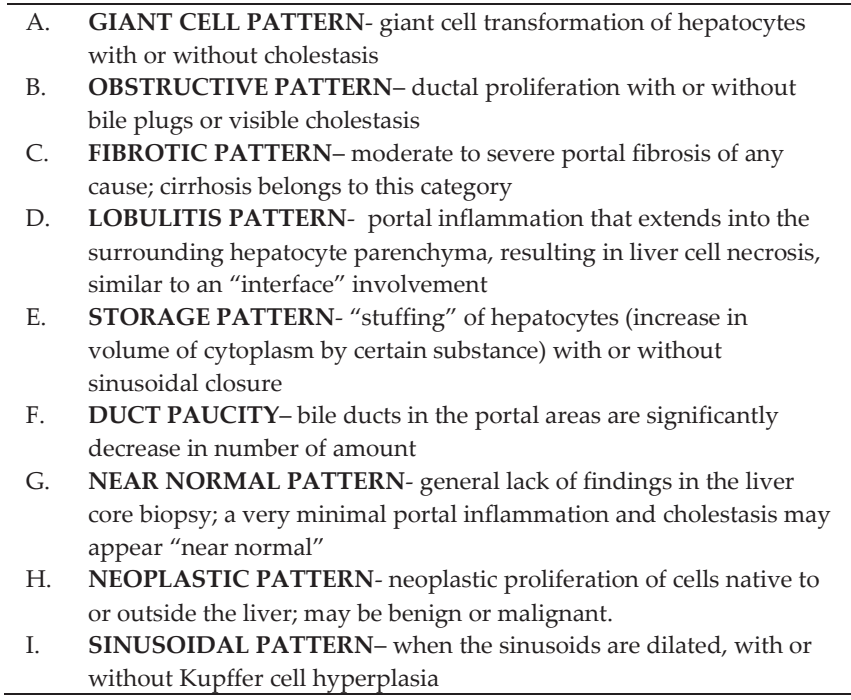

Clinical diagnoses. The patient's final clinical diagnosis was based on the features at presentation and results of biochemical, radiologic and histological investigations. The clinical diagnoses were classified into seven categories as follows: neonatal cholestasis, autoimmune liver disease, bile duct disorders, neoplastic/infiltrative, infectious liver disease, metabolic liver disease and miscellaneous. Under each category are possible diseases that have been identified in our setting (Table 2). A patient was diagnosed to have 
idiopathic neonatal hepatitis if no etiology could be identified after radiologic, metabolic and infective work-ups. A patient was said to have unspecified liver disorder when the clinical diagnosis remains unknown based on the available investigations.

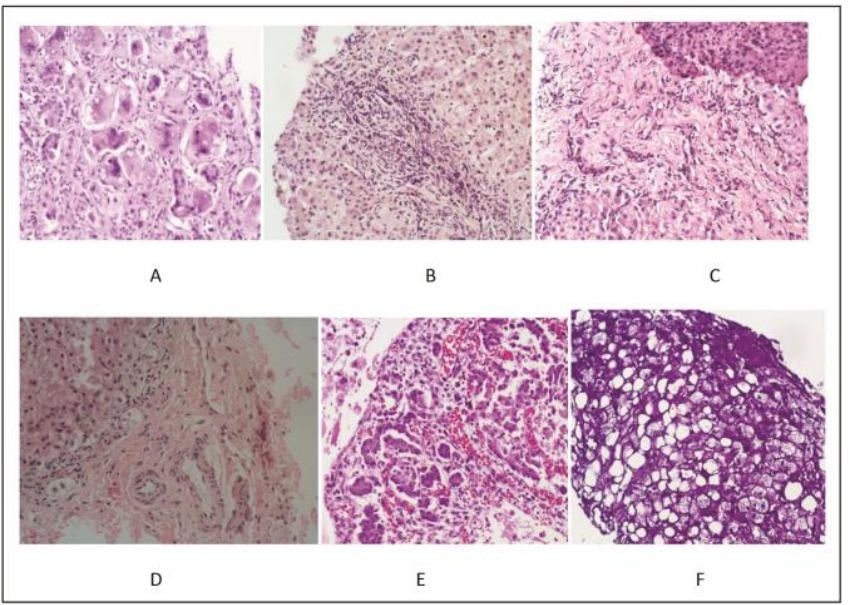

Figure 1. Predominant Histological Patterns. A. Giant cell pattern in $\mathrm{NH}$ (neonatal hepatitis); B. Obstructive pattern in EHBA (extrahepatic biliary atresia); C. Fibrotic pattern in CHF (Congenital Hepatic Fibrosis); D. Duct paucity in Alagille Syndrome; E. Neoplastic pattern in Hepatoblastoma; F. Storage pattern in metabolic disease.

Table 2. Possible Clinical Diagnoses Based on Patient's Category of Liver Disease

\begin{tabular}{ll}
\hline \multicolumn{1}{c}{ Category } & \multicolumn{1}{c}{ Clinical Diagnoses } \\
\hline Neonatal Cholestasis & Idiopatic neonatal hepatitis \\
& Extrahepatic biliary atresia \\
& Alagille syndrome \\
Autoimmune Liver Disease & Autoimmune hepatitis \\
Bile Duct Disorders & Choledochal cyst \\
& Caroli's disease \\
& Congenital hepatic fibrosis \\
& Primary Sclerosing Cholangitis \\
& Hepatoblastoma \\
Neoplastic/Infiltrative & Hepatocellular carcinoma \\
& Lymphoma \\
& Langerhans cell histiocytosis \\
& Hepatic/disseminated TB \\
& Acute viral hepatitis A or B \\
& Chronic viral hepatitis B \\
& Hepatic schistosomiasis \\
& Wilson disease \\
& Gaucher disease \\
& Weber Christian Disease \\
& Glycogen storage disease \\
& Liposomal storage disease \\
& Endocrine disorders such as hypothyroidism \\
& Acute cellular rejection \\
& Acute liver failure \\
& Drug induced hepatitis \\
& Portal vein thrombosis \\
& TB Constrictive Pericarditis \\
\hline Miscellaneous &
\end{tabular}

Outcome. The outcome of the patients were assessed using two different endpoints: $6^{\text {th }}$, and $12^{\text {th }}$ month from the time they were diagnosed to have liver disease. The patients were followed-up until June 2011, which is at least six months from the last recruitment date. The final outcome of the patients was described as follows: (1) alive with no clinical or biochemical signs of liver disease; (2) alive with sequelae if with clinical or biochemical signs of liver disease; and (3) died if patient has expired or required a liver transplant.

Statistical analysis. The data were presented as means (SD), number of frequency and percentages. Analysis was done using chi square test.

\section{Results}

There were 1185 referrals for primary liver diseases from January 2006 to December 2010 in our institution of whom 508 patients underwent liver biopsy. Fifty patients were excluded from the study for the following reasons: incomplete medical records (32), missing liver biopsy slides (8) and inadequate or poor processing of liver biopsy (10).

There were 458 patients eligible in this study, of which 12 patients had a repeat liver biopsy from 4 to 8 weeks after the first, thus a total of 470 percutaneous liver biopsy cases. These repeat liver biopsies were done for the following reasons: in nine, due to persistence of jaundice and hepatomegaly in infants with neonatal cholestasis in whom an obstructive etiology has been ruled out initially; in two in whom the initial biopsies did not correlate with the clinical and biochemical parameters; and in an 11 year old who was diagnosed to have autoimmune hepatitis with no improvement with initial immunosuppressive treatment. All 12 repeat liver biopsies were done blindly.

Of the 470 biopsies, 410 (87\%) were done blindly, while the rest were done either as ultrasound guided (31) or with a liver biopsy site previously confirmed by ultrasound (30).

Age ranged from 1 month to 18 years old, with the majority $(68 \%)$ of patients belonging to the $0-3$ months of life and $85 \%$ less than one year of age. The others were between $1-5(5.3 \%), 6-10(5.1 \%)$ and $>10$ years old $(5.5 \%)$. There was a male predominance in all age groups $(64.7 \%)$ with a male to female ratio of 1.8:1. (Table 3). The most common clinical diagnoses were those of neonatal cholestasis including idiopathic neonatal hepatitis (49\%) followed by extrahepatic biliary atresia (29\%). The 16-year-old male classified under miscellaneous with TB Constrictive Pericarditis presented with asymptomatic hepatomegaly and elevated alanine transaminase and was initially assessed as Congenital Hepatic Fibrosis, thus a liver biopsy was done. In ten patients, the diagnosis remains unknown after doing all possible investigations in our setting. These patients were classified as having unspecified liver disease. 
Table 3. Demographic and Clinical Diagnoses of 470 Patients Based on Category of Liver Disease According to Age Group, n (\%)

\begin{tabular}{|c|c|c|c|c|c|c|c|}
\hline & $\begin{array}{c}0-3 \text { months } \\
(\mathrm{n}=321)\end{array}$ & $\begin{array}{c}4-6 \text { months } \\
(n=59)\end{array}$ & $\begin{array}{c}7-11 \text { months } \\
(n=15)\end{array}$ & $\begin{array}{c}1-5 \text { years old } \\
(n=25)\end{array}$ & $\begin{array}{c}\text { 6-10 years old } \\
(n=24)\end{array}$ & $\begin{array}{c}>10 \text { years old } \\
(n=26)\end{array}$ & $\begin{array}{c}\text { Total } \\
(\mathrm{n}=470)\end{array}$ \\
\hline Mean (SD) age & $2.2(0.65)$ & $4.3(0.67)$ & $9.0(1.6)$ & $2.5(1.4)$ & $8.0(1.1)$ & $14.6(2.5)$ & \\
\hline Males, n (\%) & 216 & 34 & 10 & 19 & 11 & 15 & 348 \\
\hline \multicolumn{8}{|l|}{ Clinical diagnoses } \\
\hline I. Neonatal Cholestasis & & & & & & & \\
\hline Neonatal hepatitis & 206 & 20 & 5 & 0 & 0 & 0 & 231 \\
\hline Extrahepatic Biliary Atresia & 101 & 30 & 4 & 1 & 0 & 0 & 136 \\
\hline Alagille Syndrome & 5 & 1 & 0 & 3 & 0 & 0 & 9 \\
\hline II. Autoimmune Liver Disease & & & & & & & 5 \\
\hline Autoimmune Hepatitis & 0 & 0 & 0 & 1 & 1 & 3 & \\
\hline III. Bile Duct Disorders & & & & & & & 10 \\
\hline Congenital Hepatic Fibrosis & 0 & 0 & 0 & 1 & 3 & 0 & 4 \\
\hline Primary Sclerosing Cholangitis & 0 & 1 & 0 & 1 & 0 & 1 & 3 \\
\hline Choledochal Cyst & 2 & 0 & 0 & 0 & 0 & 0 & 2 \\
\hline Caroli's Disease & 0 & 1 & 0 & 0 & 0 & 0 & 1 \\
\hline IV. Neoplastic/Infiltrative & & & & & & & 20 \\
\hline Hepatoblastoma & 4 & 4 & 4 & 3 & 1 & 0 & 16 \\
\hline Hepatocellular Carcinoma & 0 & 0 & 0 & 0 & 0 & 1 & 1 \\
\hline Langerhans Cell Histiocytosis & 0 & 0 & 0 & 0 & 2 & 0 & 2 \\
\hline Lymphoma & 0 & 0 & 0 & 0 & 1 & 0 & 1 \\
\hline V. Infectious Liver Disease & & & & & & & 27 \\
\hline Hepatitis A & 0 & 0 & 0 & 0 & 0 & 1 & 1 \\
\hline Chronic Hepatitis B & 0 & 0 & 1 & 3 & 4 & 4 & 12 \\
\hline Acute Hepatitis B & 0 & 1 & 0 & 0 & 0 & 0 & 1 \\
\hline Hepatic tuberculosis & 0 & 0 & 0 & 0 & 4 & 4 & 8 \\
\hline Disseminated Tuberculosis & 0 & 0 & 0 & 0 & 1 & 3 & 4 \\
\hline Hepatic Schistosomiasis & 0 & 0 & 0 & 0 & 0 & 1 & 1 \\
\hline VI. Metabolic Liver Disease & & & & & & & 8 \\
\hline Wilsons disease & 0 & 0 & 0 & 0 & 1 & 1 & 2 \\
\hline Gaucher's disease & 0 & 0 & 0 & 0 & 0 & 1 & 1 \\
\hline Weber Christian Disease & 0 & 0 & 0 & 0 & 1 & 0 & 1 \\
\hline Glycogen storage disease & 1 & 0 & 0 & 1 & 0 & 0 & 2 \\
\hline Liposomal storage disease & 1 & 0 & 0 & 0 & 0 & 0 & 1 \\
\hline Endocrine disorder & 0 & 0 & 0 & 0 & 0 & 1 & 1 \\
\hline VII. Miscellaneous & & & & & & & 24 \\
\hline Acute Cellular Rejection & 0 & 0 & 0 & 5 & 0 & 0 & 5 \\
\hline Acute Liver Failure & 0 & 0 & 1 & 1 & 0 & 2 & 4 \\
\hline Portal Vein Thrombosis & 0 & 0 & 0 & 0 & 2 & 1 & 3 \\
\hline TB Constrictive Pericarditis & 0 & 0 & 0 & 0 & 0 & 1 & 1 \\
\hline Drug induced hepatitis & 0 & 0 & 0 & 0 & 0 & 1 & 1 \\
\hline Unspecified & 1 & 1 & 0 & 5 & 2 & 1 & 10 \\
\hline
\end{tabular}

Table 4. Histological Patterns of 470 Patients Investigated According to Age Group, n (\%)

\begin{tabular}{|c|c|c|c|c|c|c|c|}
\hline & $\begin{array}{c}0-3 \text { months } \\
(n=321)\end{array}$ & $\begin{array}{c}\text { 4-6 months } \\
(n=59)\end{array}$ & $\begin{array}{c}7-11 \text { months } \\
(n=15)\end{array}$ & $\begin{array}{c}1-5 \text { years old } \\
(n=25)\end{array}$ & $\begin{array}{c}\text { 6-10 years old } \\
(n=24)\end{array}$ & $\begin{array}{c}>10 \text { years old } \\
(n=26)\end{array}$ & $\begin{array}{c}\text { Total } \\
(n=470)\end{array}$ \\
\hline A. Giant Cell Pattern & $206(65)$ & $20(34)$ & $5(33)$ & 0 & 0 & 0 & $231(49.1)$ \\
\hline B. Obstructive Pattern & $70(21)$ & $15(25)$ & $1(7)$ & $1(4)$ & 0 & $1(4)$ & $88(18.7)$ \\
\hline C. Fibrotic Pattern & $34(11)$ & $18(30)$ & $3(20)$ & $5(20)$ & $9(38)$ & $6(23)$ & $75(16)$ \\
\hline D. Lobulitis/ Necrotic Pattern & 0 & $1(2)$ & $1(7)$ & $7(28)$ & $2(8)$ & $7(27)$ & $18(3.8)$ \\
\hline E. Storage Pattern & $2(<1)$ & 0 & 0 & $3(12)$ & $2(8)$ & $5(19)$ & $12(2.6)$ \\
\hline F. Duct Paucity & $5(2)$ & $1(2)$ & 0 & $3(12)$ & 0 & 0 & $9(2)$ \\
\hline G. Near Normal Pattern & 0 & 0 & $1(7)$ & $3(12)$ & $8(33)$ & $5(19)$ & $17(3.6)$ \\
\hline H. Neoplastic Pattern & $4(1)$ & $4(7)$ & $4(27)$ & $3(12)$ & $2(8)$ & $1(4)$ & $18(3.8)$ \\
\hline I. Sinusoidal Pattern & 0 & 0 & 0 & 0 & $1(4)$ & $1(4)$ & $2(0.4)$ \\
\hline
\end{tabular}

Table 4 shows that the histological patterns vary according to the age group. In infants between 0-6 months of life, a giant cell pattern was the most common histology (49.1\%) followed by an obstructive (18.7\%) and fibrotic (16\%) type. Children over one year old showed various histological patterns depending upon their primary liver pathology.
Clinical diagnoses, predominant histological pattern and outcome.

Neonatal hepatitis. Among the 231 patients with clinical diagnosis of neonatal hepatitis, 229 (99\%) had a giant cell pattern with only one with an obstructive and another with a fibrotic type. Of these, $200(87.3 \%)$ and 219 patients $(96 \%)$ were alive with normal biochemical and radiologic 
findings at 6 months and 1 year follow up, respectively, including the patient who had an obstructive pattern initially. (Table 5). All 19 patients with signs of liver disease at 6 months recovered with no evidence of liver disease one year after diagnosis. The 10 patients (4.4\%) who died occurred during the first 6 months of life.

Table 5. Association Between Predominant Histological Pattern and Outcome Among Patients with Neonatal Hepatitis and Extrahepatic Biliary Atresia at Six and Twelve Months Follow up, n (\%)

\begin{tabular}{lcc}
\hline & $\begin{array}{c}\text { Giant Cell Pattern } \\
\text { in Neonatal } \\
\text { Hepatitis } \\
(\mathbf{n}=\mathbf{2 2 9})\end{array}$ & $\begin{array}{c}\text { Obstructive/Fibrotic } \\
\text { Pattern in } \\
\text { Extrahepatic Biliary } \\
\text { Atresia }(\mathbf{n}=\mathbf{1 3 6})\end{array}$ \\
\hline Six months ${ }^{1}$ & $200(87.3)$ & 0 \\
Alive without liver disease & $19(8.3)$ & $95(70)$ \\
Alive with liver disease & $10(4.4)$ & $41(30)$ \\
Died/required liver transplant & & $4(3)$ \\
Twelve months ${ }^{2}$ & $219(96)$ & $31(23)$ \\
Alive without liver disease & 0 & $101(74)$ \\
Alive with liver disease & $10(4)$ & \\
Died/required liver transplant &
\end{tabular}

Extrahepatic biliary atresia. Among the 136 patients with clinical diagnosis of extrahepatic biliary atresia, the predominant histology was an obstructive (62\%), followed by fibrotic pattern $(38 \%)$. The data of patients with EHBA who had fibrotic and obstructive pattern were pooled as the outcome of each pattern was similar. At one year follow up, (Table 5) only four (3\%) patients have no clinical or biochemical signs of liver disease. Two of them had an obstructive and the other two with fibrotic pattern and all underwent successful Kasai portoenterostomy operation. The majority $(74 \%)$ had died or required liver transplant.

Comparison showed that the outcome was better among patients with neonatal cholestasis who had a giant cell pattern on histology as compared to those with an obstructive or fibrotic pattern at 6 months $(p<0.05)$ and 1 year of follow-up $(\mathrm{p}<0.05)$. (Table 5).

Other liver disorders. In all patients with Alagille's syndrome, primary or metastatic tumor and both chronic hepatitis B and portal vein thrombosis, the predominant histological patterns were bile duct paucity, neoplastic and near normal patterns, respectively. There was no predominant pattern among those with metabolic disorders, autoimmune, bile duct abnormalities and infective liver disease. No association could be done in the histological pattern and outcome of these patients due to the limited sample size.

Complications of liver biopsy. No patient developed hemoperitoneum, hemothorax, bile peritonitis or pneumothorax after the liver biopsy. Nine patients $(2 \%)$ developed fever which resolved within 24 hours.

\section{Discussion}

The present study shows two important findings: first, that in the local setting, pediatric liver disease is commonly seen among infants less than one year old with neonatal hepatitis and biliary atresia as the most common disorder; and second, the predominant histopathological pattern provides useful information of the underlying liver disease.

The overall prevalence of liver disease in children worldwide is not known ${ }^{2}$ and the leading causes vary in each country. ${ }^{4,5,9,12}$ In Iran ${ }^{9}$ and Pakistan, ${ }^{4}$ hemochromatosis secondary to thalassemia is the most common disorder with a prevalence of 18 and 30\%, respectively. In Nigeria, ${ }^{23}$ the most common pediatric liver disease is hepatic schistosomiasis while in China, ${ }^{12}$ liver inflammatory illnesses are commonly due to chronic viral hepatitis B and C. Neonatal cholestasis, consisting of idiopathic neonatal hepatitis and biliary atresia comprised $80 \%$ of our cases, which is higher than the $60 \%$ reported incidence of neonatal cholestasis in the United States. ${ }^{1}$

Our study showed that age is an important determinant of the type of liver disease. In infants with possible liver disease, the more common disorders to consider are neonatal hepatitis and biliary atresia, which is suspected in the presence of persistent jaundice, hepatomegaly or coagulopathy. Other differential diagnosis in this age group is Alagille's syndrome, a disease characterized by paucity of interlobular bile ducts with facial dysmorphism and cardiac, renal or vertebral anomalies. ${ }^{1}$ This was seen in five patients in our series. In the older children, infective, neoplastic, bile duct abnormalities and idiopathic liver diseases were commonly observed in our setting. Interestingly, the majority $(65 \%)$ of our patients in all age groups were males. Sex has not been previously shown to be an important determinant of liver disease in children. ${ }^{5}$

This study underscores the importance of histological assessment in the evaluation of children with liver disease. Our proposed classification allowed us to give a precise diagnosis in more than $98 \%$ of cases after considering possible differential diagnosis based on the histopathological pattern. This proves further the utility of liver biopsy in children with liver disease which can guide the clinician to prioritize the additional work-ups that may be deemed important to determine the possible etiology. Based on the available virological, serological and radiologic investigations in our institution, only ten of our patients remained to have an unidentified liver disease. However, despite its utility as a diagnostic armamentarium, liver biopsy has risk of complications as seen in $2 \%$ of our cases. All these patients developed fever which resolved within 24 hours, which may be a reaction to Midazolam, the anaesthesia used for sedation. ${ }^{18}$ A liver biopsy procedure will also require a trained physician to perform the procedure and an experienced histopathologist to interpret the specimen. ${ }^{7}$ 
The association noted between the histological pattern and outcome among infants with neonatal hepatitis confirms observation that a giant cell pattern in this group will generally have a good outcome. ${ }^{24}$ The majority of these infants will be eventually alive without liver disease at the end of 1 year from diagnosis, although we were unable to determine the etiology of the neonatal hepatitis. It might well be that there are still unrecognized viruses or perhaps a genetic factor that contributes to the increased incidence of the disease in our country. ${ }^{25}$ Among Caucasians, the most common genetic disorder causing liver disease in infants is alpha one antitrypsin deficiency, ${ }^{26}$ although we have previously shown that there is a low incidence of the disease among Filipinos. ${ }^{27}$ There are presently reports on the association of the CD14 endotoxin receptor gene among patients with idiopathic neonatal hepatitis in Taiwan ${ }^{28}$ and whether they are also important among our patients will require further investigations. In an infant however with cholestasis, it is important to confirm the diagnosis and to rule out an obstructive cause as the latter will require immediate surgical intervention. ${ }^{29}$ Age at the time of operation is an important determinant of the outcome of infants with extrahepatic biliary atresia who may have an obstructive or fibrotic pattern initially. Unfortunately, the outcome of these patients locally remains poor due to a late diagnosis, usually around the second to third month of life. ${ }^{30}$ In this subgroup, the only mode of treatment for long term survival is a liver transplant. ${ }^{31}$

\section{Conclusion}

Our study showed that majority of pediatric liver cases in our setting are infants, with neonatal hepatitis and biliary atresia as the most common etiology. Predominant histological patterns were giant cell hepatitis and obstructive type. Histological pattern of giant cell hepatitis seen in neonatal hepatitis resulted in a better outcome than the obstructive and fibrotic patterns of biliary atresia. In this regard, education and training of our physicians is important so that jaundiced infants could be immediately referred to a specialist. The etiology of neonatal cholestasis is unknown and research priorities should include understanding the pathogenesis of neonatal cholestasis, the most common pediatric liver disease locally. Moreover, the usefulness of our proposed histological patterns in interpreting liver biopsies should be investigated in other institutions.

\section{References}

1. D'Agata ID, Balistreri WF. Evaluation of liver disease in the pediatric patient. Pediatr Rev. 1999; 20(11):376-90.

2. Kim WR, Brown RS Jr,Terrault NA, El-Serag H. Burden of liver disease in the United States: Summary of a workshop. Hepatology. 2002; 36(1): 227-42.
3. Rastogi A, Krishnani N, Yachha SK, Khanna V, Poddar U, Lal R. Histopathological features and accuracy for diagnosing biliary atresia by prelaparotomy liver biopsy in developing countries. J Gastroenterol Hepatol. 2009; 24(1):97-102.

4. Ahmad M, Afzal S, Roshan E, et al. Usefulness of needle biopsy in the diagnosis of pediatric liver disorders. J Pak Med Assoc. 2005; 55(1):24-8.

5. Alam MJ, Ahmed F, Mobarak R, et al. Pattern of liver diseases in children admitted in Dhaka Shishu Hospital. Int J Hepatol. 2010; 1(3):18-24.

6. Dehghani SM, Haghighat M, Imanieh MH, Geramizadeh B. Comparison of different diagnostic methods in infants with Cholestasis. World J Gastroenterol. 2006; 12(36): 5893-6.

7. Rockey DC, Caldwell SH, Goodman ZD, Nelson RC, Smith AD; American Association for Study of Liver Diseases. Hepatology. 2009; 49(3):1017-44.

8. Spycher C, Zimmerman A, Reichen J. The diagnostic value of liver biopsy. BMC Gastroenterol. 2001; 1:12.

9. Monajemzadeh M, Tabriz HM, Mahjoub F, Fallahi G, Farahmand F. Liver needle biopsy in Iranian pediatric patients. diagnostic significance and pattern of liver diseases. Indian J Pathol Microbiol. 2009; 52(1):10-3.

10. Syn WK, Bruckner-Holt C, Farmer A, Howdle S, Bateman J. Liver biopsy in a district general hospital: Changes over two decades. World J Gastroenterol 2007; 13(40): 5336-42.

11. Al Knawy B; Shiffman M. Percutaneous liver biopsy in clinical practice. Liver Int. 2007; 27(9):1166-73.

12. Zhang HF, Yang XJ, Ziu SS, et al. Pathological changes and clinical manifestations of 1020 children with liver diseases confirmed by biopsy. Hepatobiliary Pancreat Dis Int. 2004; 3(3):395-8.

13. Alswat KA, Mumtaz K, Jafri W. Liver biopsy for histological assessment: the case in favor. Saudi J Gastroenterol 2010; 16(2):133-9.

14. Grant A, Neuberger J. Guidelines on the use of liver biopsy in clinical practice. British Society of Gastroenterology. Gut. 1999; 45 Suppl 4:1-11.

15. Lebensztejn DM, Kaczmarski M, Sobaniec-Lotowska M, Barwijuk-Machala M. Blind liver biopsy in children- diagnostic significance and complications in authors' own material. Med Sci Monit. 2000; 6(6):1155-8.

16. Chhieng DC. Fine needle aspiration biopsy of liver-an update. World J Surg Oncol. 2004; 2:5.

17. Siegel CA, Silas AM, Suriawinata AA, Van Leeuwen DJ. Liver biopsy 2005: when and how? Cleve Clin J Med. 2005; 72(3):199-224.

18. Scheimann AO, Barrios JM, Al-Tawil YS, Gray KM, Gilger MA. Percutaneous liver biopsy in children: impact of ultrasonography and spring-loaded biopsy needles. J Pediatr Gastroenterol Nutr. 2000; 31(5):536-9.

19. Sporea I, Popescu A, Sirli R. Why, who and how should perform liver biopsy in chronic liver disease. World J Gastroeterol. 2008; 14(21):3396-402.

20. Harwood J, Bishop P, Liu H, Nowicki M. Safety of blind percutaneous liver biopsy in obese children: A Retrospective Analysis. J Clin Gastroenterol. 2010; 44(10):253-5

21. Lichtman S, Guzman C, Moore D, Weber JL, Roberts EA. Morbidity after percutaneous liver biopsy. Arch Dis Child. 1987; 62(9):901-4.

22. Mueller M, Kratzer W, Oeztuerk S, et al. Percutaneous ultrasonographically guided liver punctures: an analysis of 1961 patients over a period of ten years. BMC Gastroenterol. 2012; 12:173.

23. Obafunwa JO, Elesha SO. Childhood liver diseases in Jos, Nigeria: A retrospective histopathological study. East Afr Med J. 1991; 68(9):702-6.

24. Spiroglou K, Chatziparasidis G, Karagiozoglou-Lamboudi T, Xinias J, Demertzidou V, Patsiaura K. Idiopathic neonatal hepatitis: a long term followup study. Ann Gastroenterol. 2001; 14(2):112-7.

25. Aziz S. Genetics in pediatric liver disease. J Pak Med Assoc. 2010; 60(12): 982 3.

26. De Serres FJ. Alpha-1 antitrypsin deficiency is not a rare disease but a disease that is rarely diagnosed. Environ Health Perspect. 2003; 111(16):1851-4.

27. Tan JJ, Cutiongco-dela Paz EM, Avila JM, Gregorio GV. Low incidence of alpha one antitrypsin deficiency among Filipinos with neonatal cholestasis. J Paediatr Child Health. 2006; 42(11):694-7.

28. Chou MH, Chuang JH, Eng HL, et al. Endotoxin and CD14 in the progression of biliary atresia. J Transl Med. 2010; 8:138.

29. Lai MW, Chang MH, Hsu SC, Su CT, Kao CL, Lee CY. Differential diagnosis of extrahepatic biliary atresia from neonatal hepatitis: a prospective study. J Pediatr Gastroenterol Nutr. 1994; 18: 121-7.

30. Ayaso EA, Gregorio GV, Sio JO. Outcome of extrahepatic biliary atresia after Kasai portoenterostomy: A five-year review. Phil J Pediatr. 2000; 49:194-9.

31. Lien $\mathrm{TH}, \mathrm{Chang} \mathrm{MH}, \mathrm{Wu} \mathrm{JF}$, et al. Effects of the infant stool color card screening program on 5-year outcome of biliary atresia in Taiwan. Hepatology. 2011; 53(1):202-8. 